\title{
Surveillance of Aflatoxin and Microbiota Related to Brewer's Grain Destined for Swine Feed in Argentina
}

\author{
Gisela A. Gerbaldo, ${ }^{1,2}$ Carina M. Pereyra, ${ }^{1,2}$ Lilia R. Cavaglieri, ${ }^{1,3}$ Francisco Ruiz,, 2 \\ Liliana Pascual, ${ }^{1}$ Ana M. Dalcero, ${ }^{1,2}$ and Isabel L. Barberis ${ }^{1}$ \\ ${ }^{1}$ Departamento de Microbiología e Inmunología, Universidad Nacional de Río Cuarto, Ruta 36 km. 601. (5800), \\ X5804 BYA Río Cuarto, Córdoba, Argentina \\ ${ }^{2}$ Consejo Nacional de Investigaciones Científicas y Técnicas (CONICET), Argentina \\ ${ }^{3}$ Consejo Nacional de Investigaciones Científicas y Tecnológicas (CONICET), Argentina
}

Correspondence should be addressed to Gisela A. Gerbaldo, ggerbaldo@exa.unrc.edu.ar

Received 18 December 2010; Accepted 20 February 2011

Academic Editor: Kyoung-Jin Yoon

Copyright (๑) 2011 Gisela A. Gerbaldo et al. This is an open access article distributed under the Creative Commons Attribution License, which permits unrestricted use, distribution, and reproduction in any medium, provided the original work is properly cited.

Córdoba province in the center of Argentina is an important area of swine production. The use of industry by-product (brewer's grain) as feedstuff for swine is a regular practice and increases animal performance on these animals production. The occurrence of aflatoxin contamination is global, causing severe problems especially in developing countries. No reports on aflatoxin $\mathrm{B}_{1}$ production, micoflora, and potential aflatoxin $\mathrm{B}_{1}$ producing microorganism from brewer's grain are available. The aims of this study were (1) to isolate the microbiota species from brewer's grain, (2) to determine aflatoxin $B_{1}$ natural contamination levels, and (3) to determine the ability of Aspergillus section Flavi isolates to produce aflatoxins in vitro. Physical properties, total fungal counts, lactic acid bacteria, and fungal genera distribution were determined on this substrate. In $65 \%$ of the samples, fungal counts were higher than recommended by GMP, and lactic bacterium counts ranged from $1.9 \times 10^{5}$ to $4.4 \times 10^{9} \mathrm{CFU} \mathrm{g}^{-1}$. Aspergillus spp. prevailed over other fungal genera. Aspergillus flavus was the prevalent species followed by A. fumigatus. Aflatoxin $\mathrm{B}_{1}$ levels in the samples were higher than the recommended limits $\left(20 \mathrm{ng} \mathrm{g}^{-1}\right)$ for complementary feedstuffs. Several Aspergillus section Flavi strains were able to produce aflatoxin $B_{1}$ in vitro. Inadequate storage conditions promote the proliferation of mycotoxin-producing fungal species. Regular monitoring of feeds is required in order to prevent chronic and acute toxic syndromes related to this kind of contamination.

\section{Introduction}

Traditionally, beer industry by-product (brewer's grain) is used as a feedstuff intended for swine in the central region of Argentina. Worldwide, fungal contamination of foods and feeds, with consequent mycotoxin production, is a significant problem. Previous studies performed in Brazil determined the fungal flora as well as the presence of different mycotoxins in brewer's grain and barley rootlets $[1,2]$. Aflatoxins (AFs) are highly carcinogenic and can cause acute toxicity at high concentrations [3-5]. The occurrence of AFs contamination is global, causing severe problems, especially in developing countries. Aflatoxins are of great concern because of their detrimental effects on the health of humans and animals, including carcinogenic, mutagenic, teratogenic, and immunosuppressive effects $[6,7]$. Modern agriculture and animal production systems should contemplate the use of high-quality, mycotoxin-free feedstuffs and ingredients to avoid economically important decreases in productivity $[8,9]$. A diet based exclusively on a balanced commercial feed to obtain the best product is not always an economically viable alternative. Therefore, the most efficient results can be achieved by the use of industrial by-products or other lowcost feedstuffs [10]. In Argentina, commercial feedstuffs are an important component in modern animal husbandry, but there is no information available about microbiota occurrence and aflatoxin production in brewer's grain. Therefore, the aims of this paper were to determine microbiota occurrence and to evaluate $A F B_{1}$ production on this substrate. In addition, the ability to produce $\mathrm{AFB}_{1}$ by Aspergillus section Flavi species isolated in the present study was investigated. 


\section{Materials and Methods}

2.1. Sampling. Brewer's grains samples were collected from a craft brewery located in Villa General Belgrano (31 $59^{\prime}$ S $64^{\circ} 34^{\prime}$ O), Córdoba, Argentina. These samples were collected at different times: day zero (0) (immediately after fermentation) and after seven (7) days of storage (before feeding animals). A total of 50 samples ( $3 \mathrm{~kg}$ each) of brewer's grain were taken at different times: 26 were taken at day 0 (extracted from the fermentation tanks after the process was completed), and 24 samples were taken at day 7 (taken from storage bags before feeding animals). The sampling was performed in a period from May 2008 to February 2009. Brewer's grain was composed of Pilsen malt, Cristal Kelu malt, Super Foam malt (SF 380), and malted wheat. The samples were stored in plastic bags and the storage conditions were not controlled. The primary samples were homogenized and quartered to get $1 \mathrm{~kg}$ laboratory samples. Physical properties - $\mathrm{pH}$ and water activity $\left(\mathrm{a}_{\mathrm{W}}\right)$ - data were taken as described below. Mycological evaluation was done immediately; then, all samples were stored at $-20^{\circ} \mathrm{C}$ for a week for mycotoxin analysis.

2.2. Physical Properties Determination. Determination of $\mathrm{pH}$ in brewer's grains samples was performed as follows: fifty grams of the sample were homogenized with $100 \mathrm{~mL}$ of deionized water for $5 \mathrm{~min}$ in a laboratory blender, and $\mathrm{pH}$ was measured using a calibrated $\mathrm{pH}$ meter. Water activity determinations were carried out with an AQUALAB CX2 (Decagon, Devices, Inc. USA) device according to the operator's manual. The accuracy of aw values was \pm 0.003 .

2.3. Mycological Determination. Total fungal counts were performed on dichloran rose bengal chloranphenicol agar (DRBC), a general media used for estimating total culturable mycoflora and dichloran 18\% glycerol agar (DG18), a low aw media that favours xerophilic fungi development. Quantitative enumeration was done using the surface-spread method. Ten grams of each sample were homogenized in $90 \mathrm{~mL}$ of $0.1 \%[\mathrm{w} / \mathrm{v}]$ peptone water solution for $30 \mathrm{~min}$ in an orbital shaker. Serial dilutions $\left(10^{-1}\right.$ to $\left.10^{-3}\right)$ were made, and $0.1 \mathrm{~mL}$ aliquots were inoculated in duplicate on the culture media. Plates were incubated at $25^{\circ} \mathrm{C}$ for $7-10$ days in darkness. Plates containing 10-100 colony forming units (CFU) were used for total fungal counts, and the results were expressed as $\mathrm{CFU}$ per gram of sample $\left(\mathrm{CFU} \mathrm{g}^{-1}\right)$. Representative colonies of Aspergillus were transferred for subculturing to malt extract agar (MEA) slants. Fungal species were identified based on morphological characteristics, according to the procedures and taxonomic keys of Klich [12]. The plates were incubated aerobically at $25^{\circ} \mathrm{C}$ for 7 days. The results were expressed as isolation frequency (\% of samples in which each of the genera was present) and relative density (\% of isolation of each species among strains of the same genera).

2.4. Lactic Acid Bacteria Determination. The ICMSF technique was used [13]. Ten grams (10 g) of each sample was placed aseptically in an Erlenmeyer flask containing $90 \mathrm{~mL}$ sterile $0.1 \%[\mathrm{w} / \mathrm{v}]$ peptone water solution $\left(10^{-1}\right.$ dilution $)$ and homogenized in a stomacher for $30 \mathrm{~min}$. Serial dilutions up to $10^{-6}$ were made in sterile peptone water. Subsequently, $1 \mathrm{~mL}$ was taken from each dilution and placed into sterile Petri dishes in duplicate. Temperate de Man Rogosa and Sharpe agar (MRS agar) (bioMérieux, France) [14] was poured into Petri dishes, and circular movements were performed to homogenize the content. The plates were incubated in microaerobiosis at $37^{\circ} \mathrm{C}$ for $48 \mathrm{~h}$. Only plates containing 30-300 colonies were used for the bacterial count, and results were expressed as $\mathrm{CFU} \mathrm{g}^{-1}$. Different types of colonies were subcultured in MRS broth and incubated in microaerobiosis at $37^{\circ} \mathrm{C}$ for $48 \mathrm{~h}$. Gram stain, catalase, oxidase, indole, and gelatinase tests were performed to each selected isolate [15]. Lactic acid bacteria were stored at $-80^{\circ} \mathrm{C}$ in glycerol $30 \%(\mathrm{v} / \mathrm{v})$.

2.5. Aflatoxin $B_{1}$ Analysis. A $50 \mathrm{~g}$ aliquot of each sample was extracted with $150 \mathrm{~mL}$ methanol: water $(80: 20, \mathrm{v} / \mathrm{v})$ solution for $3 \mathrm{~min}$ into a blender. The mixture was filtered through Whatman $\mathrm{N}^{\circ} 4$ filter paper (Whatman, Inc., Clifton, New Jersey, USA) and $2.5 \mathrm{~mL}$ of the filtrate was added to $2.5 \mathrm{~mL}$ of acetonitrile. This mixture was placed into a $10 \mathrm{~mL}$ test tube. Aflazon Mycosep 228 clean-up columns (MFC, Romer Labs, Inc., MO., USA) multifunctional columns were used for cleaning the extracts, following the methodology supplied by the manufacturer. The extract was forced through a frit, through a 1-way valve and through packing material. Purified extract $(4 \mathrm{~mL})$ was collected in a vial and dried under a stream of $\mathrm{N}_{2}$. Aflatoxin $\mathrm{B}_{1}$ detection and quantification was performed by high performance liquid chromatography (HPLC) according to the methodology proposed by Trucksess et al. [16]. An aliquot $(200 \mu \mathrm{L})$ was derivatized with $700 \mu \mathrm{L}$ trifluoroacetic acid:acetic acid:water $(20: 10: 70$, $\mathrm{v} / \mathrm{v})$. Chromatographic separations were performed on a reversed phase column (Silica Gel, $150 \times 4.6 \mathrm{~mm}$ id., $5 \mu$ particle size, VARIAN, Inc. Palo Alto, USA). Methanol-water $(60: 40 \mathrm{v} / \mathrm{v})$ was used as the mobile phase at a flow rate $1 \mathrm{~mL} \mathrm{~min}{ }^{-1}$. Fluorescence of AFs derivatives was recorded at $\lambda 360 \mathrm{~nm}$ excitation and $\lambda 460 \mathrm{~nm}$ emission. Calibration curves were constructed using different concentrations of $\mathrm{AFB}_{1}$ (Sigma, St. Louis, MO, USA; purity >99\%) standard solutions. Aflatoxin was quantified by correlating sample peak heights with those of standard solutions. The detection limit of the analytical method was $0.4 \mathrm{ng} \mathrm{g}^{-1}$.

2.6. Aflatoxin Production by Aspergillus Section Flavi. A total of 137 Aspergillus section Flavi strains isolated from brewer's grain were assayed for AFs production according to Geisen [17]. Strains were grown on MEA plates for 7 days at $28^{\circ} \mathrm{C}$. Three agar plugs were removed from the central area of the colony, weighed and introduced into a small vial. One $\mathrm{mL}$ chloroform was added to each vial and the mixture was centrifuged at $10000 \mathrm{rpm}$ for $10 \mathrm{~min}$. The chloroform phase was removed and evaporated to dryness under $\mathrm{N}_{2}$ flow and the residue was redissolved in $200 \mu \mathrm{L}$ chloroform. Extracts were analyzed by thin layer chromatography (TLC) on silica gel 60 F254 TLC aluminum sheets $(20 \times 20 \mathrm{~cm}$, 
TABLE 1: Values of $\mathrm{pH}$ and $\mathrm{a}_{\mathrm{W}}$ from brewer's grain at days 0 and 7 of storage.

\begin{tabular}{lcccc}
\hline Sampling (days) & & $\mathrm{pH}$ & & $\mathrm{a}_{\mathrm{W}}^{*}$ \\
& Range $^{\dagger}$ & & Mean $\pm \mathrm{SD}^{\ddagger}$ & Mean \pm SD \\
\hline 0 & $4.44-7.43$ & $5.67 \pm 1.09$ & $0.990-0.995$ & $0.992 \pm 0.002$ \\
7 & $4.22-6.95$ & $5.25 \pm 0.96$ & $0.985-0.994$ & $0.989 \pm 0.003$ \\
\hline
\end{tabular}

*Water activity.

${ }^{\dagger}$ Minimum and maximum values.

₹ Standard deviation.

$250 \mu \mathrm{m}$ thickness, Merck, Germany). The developing solvent was chloroform:acetone $(90: 10, \mathrm{v} / \mathrm{v})$. Detection limit of the method was $5 \mathrm{ng} \mathrm{g}^{-1}$. The plates were observed under UV light $(360 \mathrm{~nm})$ and the $\mathrm{AFB}_{1}$ concentration was determinate by visual comparison between fluorescence intensities of toxin and standard spots.

2.7. Statistical Analysis. Data analyses were performed by analysis of variance. Fungal and bacterial counts were transformed to $\log _{10}(x+1)$ to obtain the homogeneity of variance. Means were compared using Fisher's protected Least Significant Difference (LSD) test [18]. The analysis was conducted using PROC GLM in SAS (SAS Institute, Cary, NC).

\section{Results}

3.1. Physical Properties Determination. Table 1 shows the range, mean, and standard deviation of $\mathrm{pH}$ and $\mathrm{a}_{\mathrm{W}}$ values at day 0 and after 7 days of storage. The $\mathrm{pH}$ values ranged from 4.22 to 7.43 , whereas a values were over 0.989 in all the tested samples. Differences among $\mathrm{pH}$ and $\mathrm{a}_{\mathrm{w}}$ values of the samples after the storage period were not statistically significant $(P>.05)$.

3.2. Mycological Determination. Table 2 shows fungal counts on DRBC and DG18 media as well as the percentage of samples exceeding the limit proposed as a hygienic quality parameter for feeds. Samples collected after 7 days of storage showed higher contamination than those collected at day 0 . Several samples showed high xerophilic fungus counts. The percentage of samples above the maximum allowed limit of $1 \times 10^{4} \mathrm{CFU} \mathrm{g}^{-1}$ [11] was over $62 \%$ in DRBC and DG18 media in both sampling periods.

Figure 1 shows fungal counts analyzed monthly on DRBC and DG18 media. November, December, and January were the months with the highest counts obtained on both culture media $(P<.05)$ at day 0 , whereas October and January had the highest fungal counts at day 7 of storage. Months with lower fungal counts had statistically significant differences in DRBC between tested periods. Fungal enumeration in DG18 at days 0 and 7 of storage showed statistically significant differences in tested periods, except in July and August.

Figure 2 shows the isolation frequency (\%) of different fungal genera and yeasts. Yeasts were isolated in $75 \%$ of day 0 and day 7 samples. Aspergillus was the most frequently isolated fungal genus (77 and 74\%, resp.) followed by Penicillium spp. (65 and 52\%). The genera isolated with lower

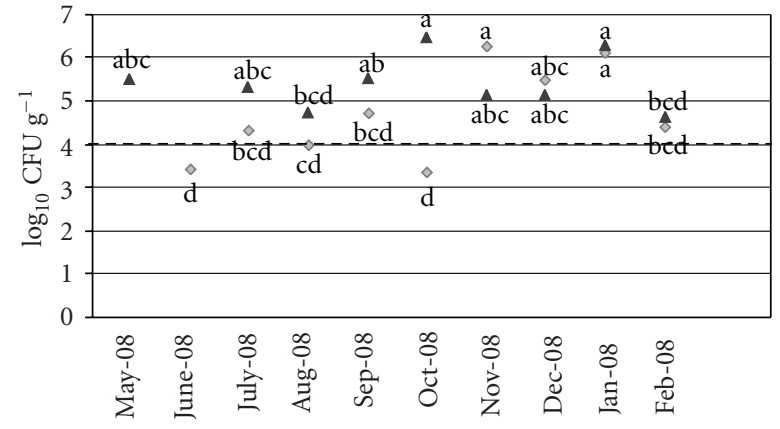

(a)

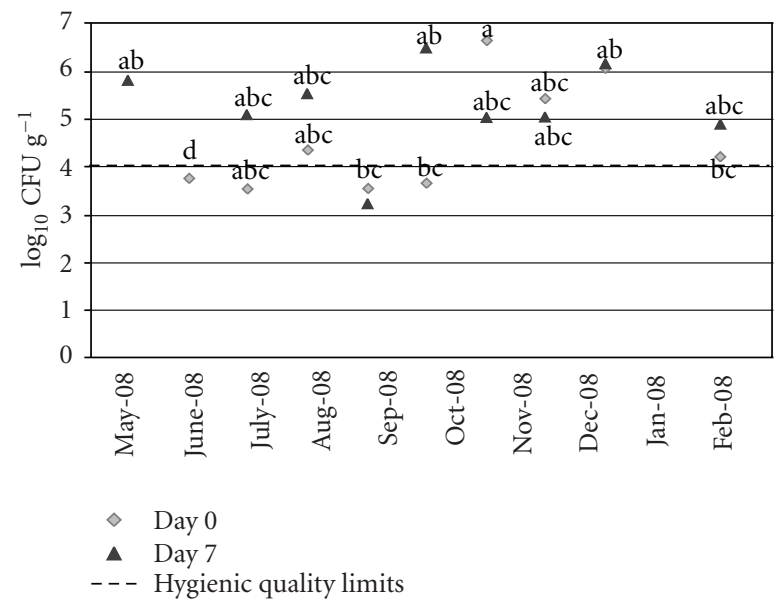

(b)

FIGURE 1: Fungal counts on DRBC (a) and DG18 (b) media during the sampling period May 2008-February 2009. Hygienic quality limits $\left(1.0 \times 10^{4} \mathrm{CFU} \mathrm{g}^{-1}\right)$ were determined according to GMP [11]. Values with letters in common are not statistically different $(P<.05)$.

frequencies were at day 0 and day 7 of storage Clado-sporium spp. (31 and 26\%), Alternaria spp. (15 and 17\%), and Fusarium spp. (6 and $4 \%$ ).

Figure 3 shows the relative density of the isolated Aspergillus species. Aspergillus flavus was the most frequently isolated species (75 and $92 \%$ density at day 0 and day 7 ) followed by A. fumigatus (22 and 4\%) and A. niger aggregate (2 and $1 \%)$.

3.3. Bacteriological Determination. Table 3 shows the LAB counts obtained from brewer's grain at different sampling periods. Counts ranged from $1.9 \times 10^{5}$ to $4.4 \times 10^{9} \mathrm{CFU} \mathrm{g}^{-1}$ whereas mean levels were similar at day 0 and after 7 days of storage. 
TABLE 2: Fungal counts $\left(\mathrm{CFU} \mathrm{g}^{-1}\right)$ in DRBC and DG18 media from brewer's samples.

\begin{tabular}{|c|c|c|c|c|}
\hline \multirow{3}{*}{ Sampling (days) } & \multicolumn{4}{|c|}{ Fungal counts $\left(\mathrm{CFU} \mathrm{g}^{-1}\right)^{*}$} \\
\hline & \multicolumn{2}{|c|}{$\mathrm{DRBC}^{\dagger}$} & \multicolumn{2}{|c|}{ DG1 $8^{\ddagger}$} \\
\hline & Range $^{\S}$ & Low quality $(\%)^{\dagger \dagger}$ & Range & Low quality (\%) \\
\hline 0 & $1.0 \times 10^{2}-3.9 \times 10^{6}$ & 62 & $3.0 \times 10^{2}-8.0 \times 10^{6}$ & 73 \\
\hline 7 & $6.8 \times 10^{3}-6.6 \times 10^{6}$ & 91 & $1.0 \times 10^{3}-6.6 \times 10^{6}$ & 83 \\
\hline
\end{tabular}

${ }^{*} \mathrm{CFU} \mathrm{g}^{-1}$ : colony forming units per gram of sample.

${ }^{\dagger}$ DRBC: dichloran rose bengal chloranphenicol agar.

${ }^{\ddagger}$ DG18: dichloran $18 \%$ glycerol agar.

$\S$ Minimum and maximum count values.

${ }^{\dagger}$ Percentages of samples that exceed limits to hygienic quality of feeds $\left(1 \times 10^{4} \mathrm{CFU} \mathrm{g}^{-1}\right)$ established by Good Manufacturing Practices [11].

TABLE 3: Lactic acid bacteria counts $\left(\mathrm{CFU} \mathrm{g}^{-1}\right)$ from brewer's grain at days 0 and 7 of storage.

\begin{tabular}{lcc}
\hline Sampling (days) & \multicolumn{2}{c}{$\begin{array}{c}\text { Counts of } \mathrm{LAB}^{*}\left(\mathrm{CFU} \mathrm{g}^{-1}\right)^{\dagger} \\
\text { Range }^{\ddagger}\end{array}$} \\
\hline 0 & $1.9 \times 10^{5}-2.7 \times 10^{9}$ & $4.9 \times 10^{8} \pm 6.9 \times 10^{8}$ \\
7 & $1.2 \times 10^{7}-4.4 \times 10^{9}$ & $7.1 \times 10^{8} \pm 1.2 \times 10^{9}$ \\
\hline
\end{tabular}

* LAB: lactic acid bacteria.

${ }^{\dagger} \mathrm{CFU} \mathrm{g}^{-1}$ : colony forming units per gram.

${ }^{\ddagger}$ Minor and major values.

$\S$ Mean values \pm standard deviation $(\mathrm{SD})$.

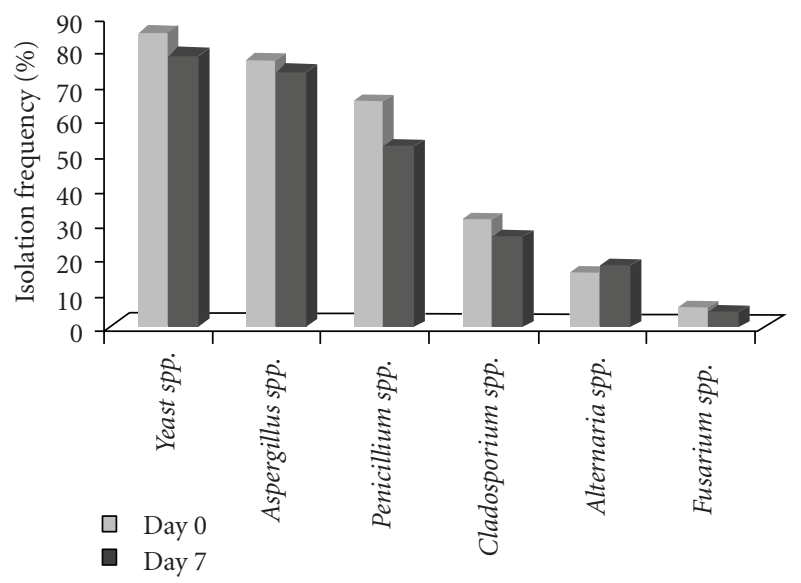

FIGURE 2: Isolation frequency (\%) of different fungal genera isolated from brewer's grains at days 0 and 7 of storage.

Figure 4 shows LAB counts analyzed monthly in DRBC and DG18 media. Statistically significant LAB counts between the two sampling periods were evident only in September and October. From August to September, a decrease in LAB counts was observed with statistically significant differences between the sampling periods. Lower counts were observed from May to July and no statistically significant differences were found between tested sampling periods.

3.4. Aflatoxin Production by Aspergillus Section Flavi. Table 4 shows the $\mathrm{AFB}_{1}$ production $\left(\mu \mathrm{g} \mathrm{g}^{-1}\right)$ by Aspergillus section
Flavi species. From a total of 138 Aspergillus section Flavi isolates tested, $89.3 \%$ of isolates from day 0 samples and $76.3 \%$ of isolates from day 7 samples were able to produce $\mathrm{AFB}_{1}$ in vitro. The highest level of $\mathrm{AFB}_{1}$ produced was $32.14 \mathrm{mg} \mathrm{kg}^{-1}$. Only one strain was able to produce both $\mathrm{AFB}_{1}\left(2.86 \mu \mathrm{g} \mathrm{g}^{-1}\right)$ and $\mathrm{AFG}_{1}\left(7.14 \mu \mathrm{g} \mathrm{g}^{-1}\right)$.

3.5. Aflatoxin $B_{1}$ Analysis. Table 5 shows the $\mathrm{AFB}_{1}$ incidence in brewer's grain samples. Over $50 \%$ of the samples were naturally contaminated with $\mathrm{AFB}_{1}$ at the two sampling points tested. Samples collected at 0 days (14) and samples collected at day 7 of storage (33) showed $\mathrm{AFB}_{1}$ levels exceeding the maximum allowed for pig feedstuffs.

\section{Discussion}

The analysis of physical parameters revealed that $\mathrm{pH}$ of the samples was slightly acid and did not show significant changes during storage. The same result was observed with $\mathrm{a}_{\mathrm{W}}$ that showed high values at both sampling times. Both physical factors, $\mathrm{pH}$ and $\mathrm{a}_{\mathrm{w}}$, were favorable for fungal development and can lead to nutritional quality and safety reduction of the feed. In this study, high fungal contamination was found. Over $50 \%$ of the samples exceeded the maximum allowed limit $\left(1 \times 10^{4} \mathrm{CFU} \mathrm{g}^{-1}\right)$ that determines the hygienic quality of animal feeds [11]. These results suggest a high fungal activity which could affect the palatability of feed and reduce nutrients absorption [19]. Fungal counts were similar to other authors who studied barley rootlets and disagree with other studies who obtained mean fungal counts below $1 \times 10^{3} \mathrm{CFU} \mathrm{g}^{-1}$. In warmer months, higher fungal counts were found at both sampling periods $[1,20]$. In contrast, Cavaglieri et al. [1] found that fungal counts were higher between April and June. This difference could be related to the climatic factor of the place where samples were extracted, as their sampling region in Brazil was warmer than the region in Argentina where the study was done.

Mycoflora analysis revealed the presence of fungal species partially similar for a study made in the same substrate [2] We both agree that Aspergillus spp. was the most frequently isolated toxicogenic genus. However, Simas et al. [2] found Fusarium spp. as the second prevalent genus, while in the present study Fusarium spp. were found in low proportion. Another genus isolated with high frequency was Penicillium 
TABLE 4: Aflatoxin $B_{1}$ production by Aspergillus section Flavi strains isolated from brewer's grain.

\begin{tabular}{|c|c|c|c|c|}
\hline \multirow{2}{*}{ Sampling (days) } & \multirow{2}{*}{ Positive strains* } & \multirow{2}{*}{$\%$} & \multicolumn{2}{|c|}{ Aflatoxin $\mathrm{B}_{1}\left(\mu \mathrm{g} \mathrm{g}^{-1}\right)^{\dagger}$} \\
\hline & & & Range & Mean level $\pm \mathrm{SD}^{\ddagger}$ \\
\hline 0 & $50 / 56$ & 89.3 & $0.6-26.5$ & $5.0 \pm 3.6$ \\
\hline 7 & $61 / 80$ & 76.3 & $0.2-32.1$ & $4.9 \pm 3.7$ \\
\hline
\end{tabular}

* Number of producer strains versus total strains.

${ }^{\dagger}$ Minor and major levels of $\mathrm{AFB}_{1}$.

${ }^{\ddagger}$ Mean level of $\mathrm{AFB}_{1} \pm$ standard deviation (SD).

TABLE 5: Incidence of AFB1 in brewer's grain at 0 and 7 days of storage.

\begin{tabular}{lcccc}
\hline Sampling (days) & Positive samples (\%) & \multicolumn{2}{c}{$\begin{array}{c}\text { Aflatoxin } \mathrm{B}_{1}\left(\mathrm{ng} \mathrm{g}^{-1}\right)^{*} \\
\text { Mean level } \pm \mathrm{SD}^{\dagger}\end{array}$} & $\mathrm{Over} \mathrm{limit}^{\ddagger}(\%)$ \\
\hline 0 & 57 & $5.40-26.88$ & $11.76 \pm 9.15$ & 25 \\
7 & 50 & $4.32-446.40$ & $256.96 \pm 150.96$ & 67 \\
\hline
\end{tabular}

${ }^{*}$ Minor and major levels of $\mathrm{AFB}_{1}$.

${ }^{\dagger}$ Mean level of $\mathrm{AFB}_{1} \pm$ standard deviation (SD).

‡Percentage of samples with $\mathrm{AFB}_{1}$ levels over limits established by GMP [11] $20 \mathrm{ng} \mathrm{g}^{-1}$.

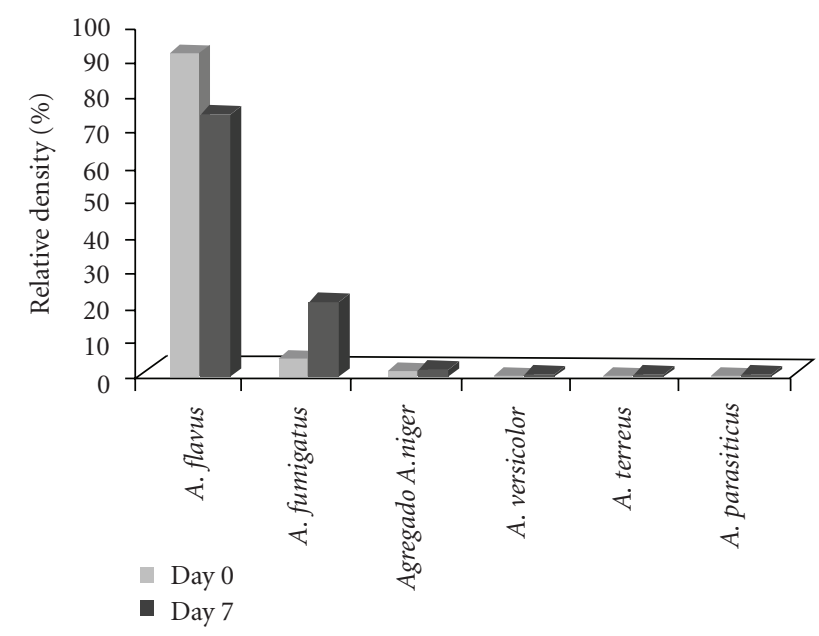

Figure 3: Relative density (\%) of Aspergillus species isolated from brewer's grain at days 0 and 7 of storage destined to pig production.

spp. This result agrees with another study that found a high frequency of Penicillium and Aspergillus species were isolated from barley grains [21]. Simas et al. and Lyberg et al. $[2,20]$ found other fungal species such as Alternaria spp. and Cladosporium spp., also comparable to these results.

The high isolation frequency of $A$. flavus found in our study agrees with Medina et al. [22] who studied barley mycoflora in Spain. In addition, in other investigations [20-22] other Aspergillus species such as A. fumigatus, A. niger aggregate, and $A$. versicolor were isolated that also coincide with our results. The predominance of Aspergillus spp. in all studied samples could be the result of the processing and storage conditions of brewer's grain that favored the development of storage contaminant fungi. A high percentage of yeast in the substrate in combination with the lactobacilli may lead to a mutual benefit [23].

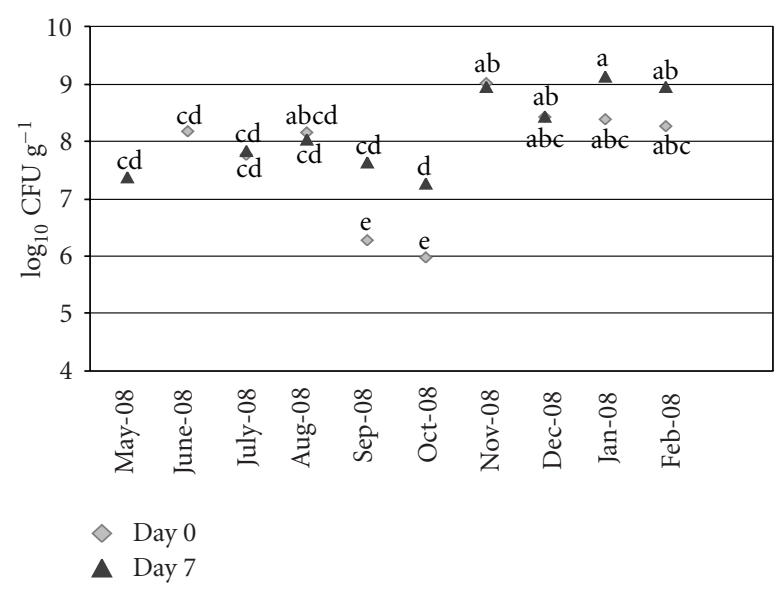

FIGURE 4: Lactic acid bacteria counts on MRS medium during the sampling period May 2008-February 2009. Values with letters in common are not statistically significant $(P<.05)$.

In this study, LAB and fungal counts followed the same tendency; months with higher temperatures showed higher $\mathrm{LAB}$ counts. This fact led us to conclude that isolated $\mathrm{LAB}$ counts were maintained through storage time in the analyzed substrate. Several microorganisms such as LAB have been reported to bind or degrade mycotoxins in foods and feeds $[24,25]$. These findings further support the use of specific LAB strains to bind AFs in brewer's grains $[6,26]$.

Over 70\% of Aspergillus section Flavi isolates showed the ability to produce $\mathrm{AFB}_{1}$. In contrast for a similar study, a smaller number of strains from malted barley were able to produce $\mathrm{AFB}_{2}, \mathrm{AFG}_{1}$, and $\mathrm{AFG}_{2}$ [22]. Although average $\mathrm{AFB}_{1}$ levels were similar, the highest concentrations doubled those found in the present study.

Natural contamination $\mathrm{AFB}_{1}$ levels from brewer's grain samples in our study were higher than those obtained by 
Simas et al. [2] in Brazil. Similar levels were reported by other authors in corn, peanuts, and their derivatives [27, 28]. Regulations on standard products in the animal feed sector established that the current maximum permitted level for $\mathrm{AFB}_{1}$ is $20 \mathrm{ngg}^{-1}$ [11]. In this study, $25 \%$ and $67 \%$ of the samples at 0 and 7 days of storage, respectively, showed $\mathrm{AFB}_{1}$ levels higher than the recommended limits for complementary feedstuffs.

The presence of mycotoxins indicates the existence of fungal contamination. Regular monitoring of feeds is required in order to prevent chronic and acute toxic syndromes related to this kind of contamination. Inadequate storage conditions promote the proliferation of mycotoxin-producing fungal species. Future studies should be conducted to evaluate the potential probiotic properties or detoxificant abilities of the associated yeast and LAB flora. These properties could reduce the aflatoxicoses and minimize economic losses in animal production. This is the first scientific report on surveillance on natural microbiota, potential $\mathrm{AFB}_{1}$ producers, and the occurrence of contamination of $\mathrm{AFB}_{1}$ in by-products obtained from beer industry by-products intended as complementary feedstuffs for pig performance in Argentina.

\section{Acknowledgments}

This work was carried out thanks to grants from SECYTUNRC, Ministerio de Ciencia y Tecnología de Córdoba, ANPCYT-PICT, and ANPCYT-PICT-CNPq.

\section{References}

[1] L. R. Cavaglieri, K. M. Keller, C. M. Pereyra et al., "Fungi and natural incidence of selected mycotoxins in barley rootlets," Journal of Stored Products Research, vol. 45, no. 3, pp. 147-150, 2009.

[2] M. M. S. Simas, M. B. Botura, B. Correa et al., "Determination of fungal microbiota and mycotoxins in brewers grain used in dairy cattle feeding in the State of Bahia, Brazil," Food Control, vol. 18, no. 5, pp. 404-408, 2007.

[3] B. Kabak, A. D. W. Dobson, and I. Var, "Strategies to prevent mycotoxin contamination of food and animal feed: a review," Critical Reviews in Food Science and Nutrition, vol. 46, no. 8, pp. 593-619, 2006.

[4] A. Khanafari, H. Soudi, and M. Miraboulfathi, "Biocontrol of Aspergillus flavus and aflatoxin $\mathrm{B}_{1}$ production in corn," Iranian Journal of Environmental Health Science and Engineering, vol. 4, no. 3, pp. 163-168, 2007.

[5] G. D. Osweiler, "Mycotoxins. Contemporary issues of food animal health and productivity," The Veterinary Clinics of North America. Food Animal Practice, vol. 16, no. 3, pp. 511530, 2000.

[6] C. A. Haskard, H. S. El-Nezami, P. E. Kankaanpää, S. Salminen, and J. T. Ahokas, "Surface binding of aflatoxin B by lactic acid bacteria," Applied and Environmental Microbiology, vol. 67, no. 7, pp. 3086-3091, 2001.

[7] G. S. Murthy, D. E. Townsend, G. L. Meerdink, G. L. Bargren, M. E. Tumbleson, and V. Singh, "Effect of aflatoxin $B_{1}$ on drygrind ethanol process," Cereal Chemistry, vol. 82, no. 3, pp. 302-304, 2005.
[8] S. Pousga, H. Boly, J. E. Lindberg, and B. Ogle, "Evaluation of traditional sorghum (Sorghum bicolor) beer residue, shea-nut (Vitellaria paradoxa) cake and cottonseed (Gossypium Spp) cake for poultry in Burkina Faso: availability and amino acid digestibility," International Journal of Poultry Science, vol. 6, no. 9, pp. 666-672, 2007.

[9] Y. N. Yin, L. Y. Yan, J. H. Jiang, and Z. H. Ma, "Biological control of aflatoxin contamination of crops," Journal of Zhejiang University, vol. 9, no. 10, pp. 787-792, 2008.

[10] G. Capra, A. Echenique, R. Bauza, and H. Petrocelli, "Sistemas de producción de cerdos en el Uruguay," Revista del Plan Agropecuario, pp. 47-52, 2003.

[11] Good Manufacturing Practice, "GMP Certification Scheme Animal Feed Sector 2006, Appendix 1. Product standards; regulations on product standards in the animal feed sector," GMP, vol. 14, pp. 1-39, 2008.

[12] M. A. Klich, Identification of Common Aspergillus Species, Centraalbureau voor Schimmelcultures, Utrecht, Netherlands, 2002.

[13] International Commission on Microbiological Specification for Foods (ICMSF), "Microbiología de los Alimentos," Editorial Acribia. Zaragoza España, vol. 1, p. 431, 1996.

[14] J. De Man, M. Rogosa, and M. Sharpe, "A medium for cultivation of Lactobacilli," Journal of Applied Bacteriology, vol. 23, pp. 130-135, 1960.

[15] P. Sneath, N. S. Mair, E. Sharpe, and J. G. Holt, Bergey's Manual of Systematic Bacteriology, vol. 2, 1986.

[16] M. W. Trucksess, M. E. Stack, S. Nesheim, R. H. Albert, and T. R. Romer, "Multifunctional column coupled with liquid chromatography for determination of aflatoxins $B_{1}, B_{2}, G_{1}$, $\mathrm{G}_{2}$ in corn, almonds, brazil nuts, peanuts, and pistachio nuts: collaborative study," Journal of Association of Official Analytical Chemists International, vol. 77, no. 6, pp. 1512-1521, 1994.

[17] R. Geisen, "Multiplex polymerase chain reaction for the detection of potential aflatoxin and sterigmatocystin producing fungi," Systematic and Applied Microbiology, vol. 19, no. 3, pp. 388-392, 1996.

[18] G. P. Quinn and M. J. Keough, Experimental Design and Data Analysis for Biologists, Cambridge University Press, Cambridge, UK, 2002.

[19] C. M. Pereyra, L. R. Cavaglieri, S. M. Chiacchiera, and A. M. Dalcero, "Fungi and mycotoxins in feed intended for sows at different reproductive stages in Argentina," Veterinary Medicine International, vol. 2010, Article ID 569108, 7 pages, 2010.

[20] K. Lyberg, M. Olstorpe, V. Passoth, J. Schnürer, and J. E. Lindberg, "Biochemical and microbiological properties of a cereal mix fermented with whey, wet wheat distillers' grain or water at different temperatures," Animal Feed Science and Technology, vol. 144, no. 1-2, pp. 137-148, 2008.

[21] V. Baliukoniene, B. Bakutis, and H. Stankevicius, "Mycological and mycotoxicological evaluation of grain," Annals of Agriculture and Environmental Medicine, vol. 10, no. 2, pp. 223-227, 2003.

[22] A. Medina, F. M. Valle-Algarra, R. Mateo, J. V. GimenoAdelantado, F. Mateo, and M. Jiménez, "Survey of the mycobiota of Spanish malting barley and evaluation of the mycotoxin producing potential of species of Alternaria, Aspergillus and Fusarium," International Journal of Food Microbiology, vol. 108, no. 2, pp. 196-203, 2006.

[23] F. Wang and N. Nishino, "Ensiling of soybean curd residue and wet brewers grains with or without other feeds as a total mixed ration," Journal of Dairy Science, vol. 91, no. 6, pp. 2380-2387, 2008. 
[24] E. M. Bueno, G. Laevsky, and G. A. Barabino, "Enhancing cell seeding of scaffolds in tissue engineering through manipulation of hydrodynamic parameters," Journal of Biotechnology, vol. 129, no. 3, pp. 516-531, 2007.

[25] M. P. Mokoena, P. K. Chelule, and N. Gqaleni, "The toxicity and decreased concentration of aflatoxin $\mathrm{B}$ in natural lactic acid fermented maize meal," Journal of Applied Microbiology, vol. 100, no. 4, pp. 773-777, 2006.

[26] A. Hernandez-Mendoza, H. S. Garcia, and J. L. Steele, "Screening of Lactobacillus casei strains for their ability to bind aflatoxin $\mathrm{B}_{1}$," Food and Chemical Toxicology, vol. 47, no. 6, pp. 1064-1068, 2009.

[27] M. J. M. Batatinha, M. M. Santos, M. B. Botura et al., "Ocorrência de aflatoxinas emamendoim e seus produtos comercializados no Estado da Bahia duranteo ano de 2002," Revista Do Instituto Adolfo Lutz, vol. 62, pp. 183-187, 2002.

[28] A. R. P. L. Bautista, M. Z. A. Oliveira, M. S. Miranda, and L. A. Sales, "Aflatoxinas em grãos de milho armazenado no Estado da Bahia," Revista Brasileira de Toxicologia, vol. 2, pp. 24-25, 1989. 

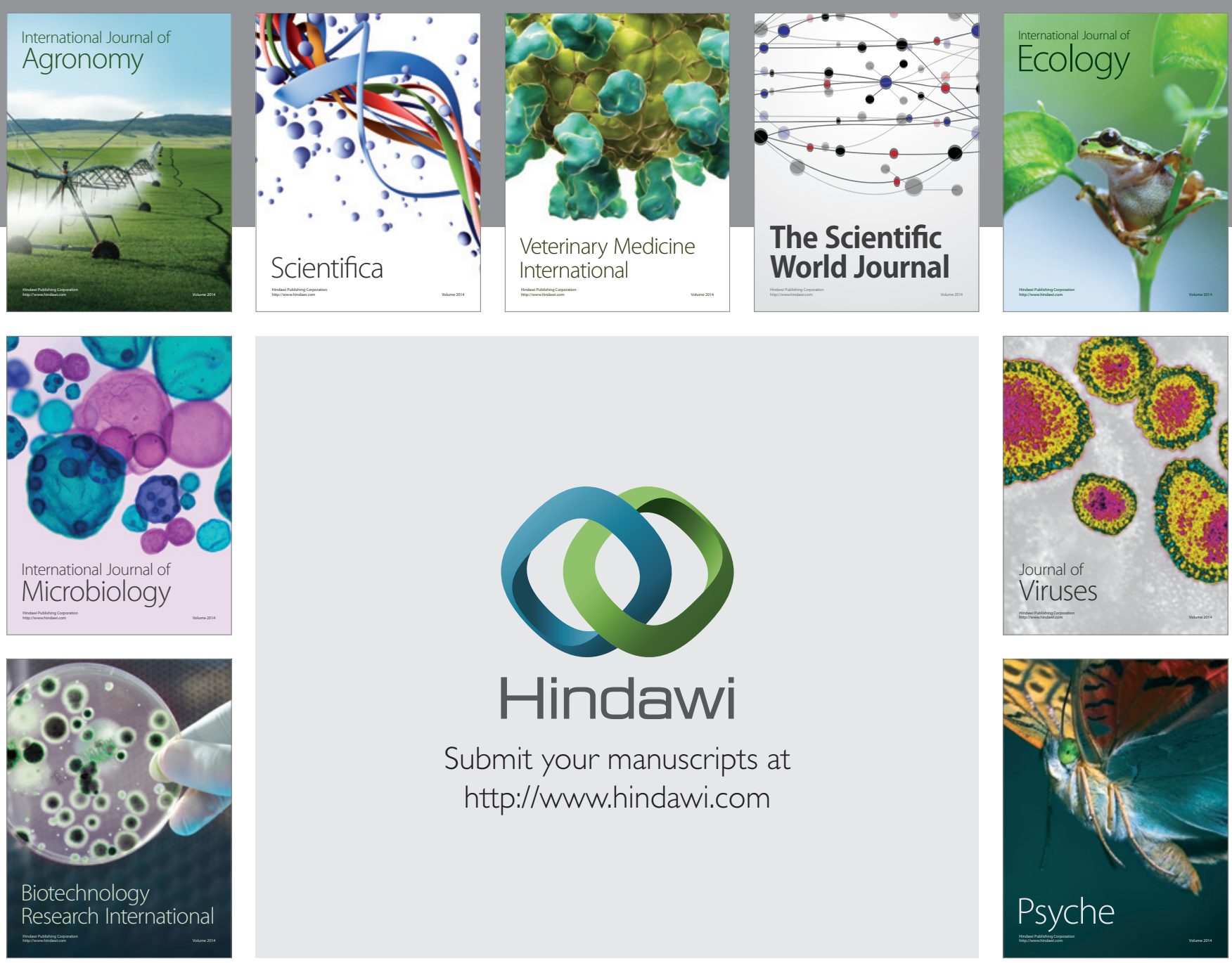

Submit your manuscripts at

http://www.hindawi.com
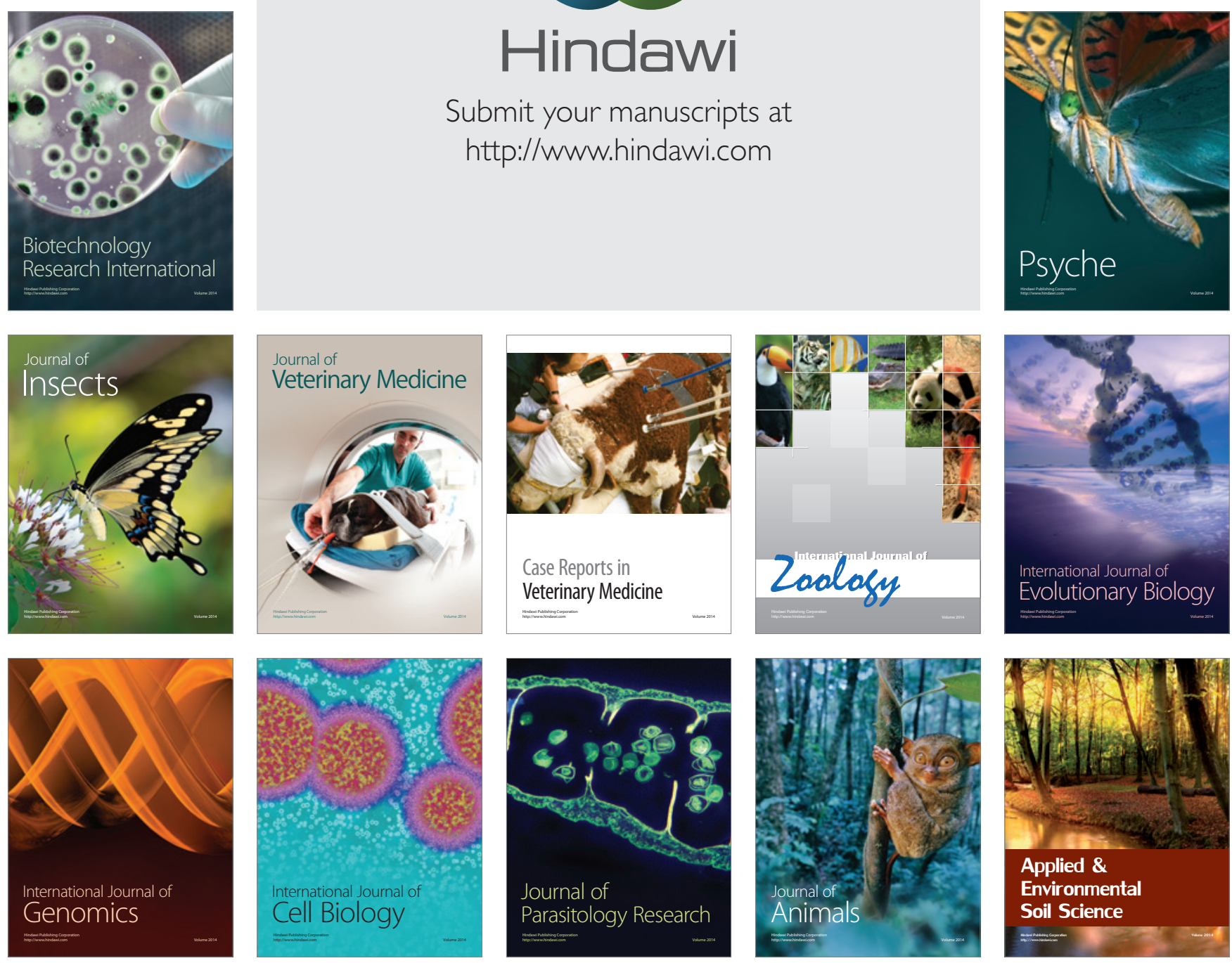